\title{
PREDIKSI JUMLAH PENJUALAN PADA TOKO MAKMUR JAYA ELEKTRONIK DENGAN REGRESI LINIER
}

\author{
Dewi yulrahmah*1, Nur Nafi'iyah ${ }^{2}$ \\ ${ }^{1,2}$ Universitas Islam Lamongan; Jalan Veteran Nomor 53A Lamongan \\ Jurusan Teknik Informatika, Fakultas Teknik

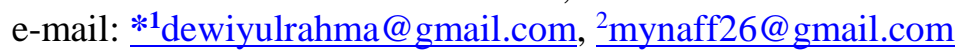

\begin{abstract}
Abstrak-Toko Makmur Jaya Elektronik merupakan toko yang bergerak di toko elektronik. Karena jumlah permintaan barang di setiap bulan kurang menentu, maka membuat pemilik toko kesulitan dalam menyediakan stok barang setiap bulan. Jika persediaan stok barang kurang maka membuat toko kehilangan laba dari perjualan. Tujuan penelitian ini untuk menentukan stok persediaan barang di bulan berikutnya menggunakan algoritma regresi linier berganda. Metode yang digunakan dalam penelitian ini adalah regresi linier berganda dengan inputan jenis barang, bulan, dan outputnya adalah stok barang. Barang yang akan diprediksi adalah kulkas dan televisi selama 3 tahun, sebanyak 72 baris dataset. Hasil perhitungan menunjukkan bahwa metode regresi linier nilai MAPE sebesar 27,291 dan MAD sebesar 9,916.
\end{abstract}

Kata kunci: peramalan, regresi linier berganda, kulkas dan televisi.

\section{Pendahuluan (INF_Heading 1)}

Banyak aplikasi yang dapat digunakan menghitung nilai korelasi atau mencari persamaan garis linear dari suatu data[1]. Salah satunya dapat menggunakan SPSS atau MiniTab. Beberapa aplikasi tersebut adalah tool yang dapat digunakan untu mengolah data yang diinputkan.

Regresi linear merupakan persamaan garis dari dataset yang dikumpulkan. Regresi linear juga dapat menghasilkan nilai korelasi[2]. Regresi linear digunakan untuk memprediksi harga jual mobil bekas dengan nilai korelasi 0,929[2].

Regresi linear merupakan suatu garis yang merepresentasikan suatu data yang berkorelasi. Di mana dataset yang sudah ditentukan variabel dependen dan independen dicari persamaan garisnya, selanjutnya dilakukan ujicoba[3].

Algoritma regresi linear sangat baik digunakan untuk melakukan prediksi atau mencari nilai korelasi. Karena beberapa algoritma yang menggunakan dataset untuk memprediksi mempunyai nilai akurasi yang baik. Misalnya dalam penelitian Nur Nafi'iyah menyebutkan perbandingan algoritma regresi linear dan backpropagation dalam memprediksi harga emas sangat baik, dapat dilihat dari nilai hanya $0,5[4]$.

Regresi linear dapat digunakan untuk memprediksi kebutuhan obat berdasarkan pesanan dan data penjualan. Langkah dalam melakukan prediksi dengan menentukan variabel $\mathrm{x}$ dan $\mathrm{y}$, kemudian mencari persamaan liniernya. Regresi linear dapat digunakan untuk memprediksi kebutuhan obat agar dapat membantu distributor[5].

Regresi linier dapat digunakan untuk memprediksi nilai ujian akhir mahasiswa. Regresi linier merupakan metode yang mencari nilai persamaan garis linier. Dari persamaan yang dihasilkan digunakan untuk memprediksi data baru[6].

Tujuan penelitian ini membangun aplikasi yang dapat memprediksi stok persediaan barang pada toko Makmur Jaya menggunakan regresi linear berganda.

\section{LANDASAN TEORI}

Regresi linier adalah metode statistika yang digunakan untuk membentuk model hubungan antar variabel dependen dengan variabel independen[7].

Gambar 1 merupakan suatu grafik yang menampilkan persamaan garis linier.

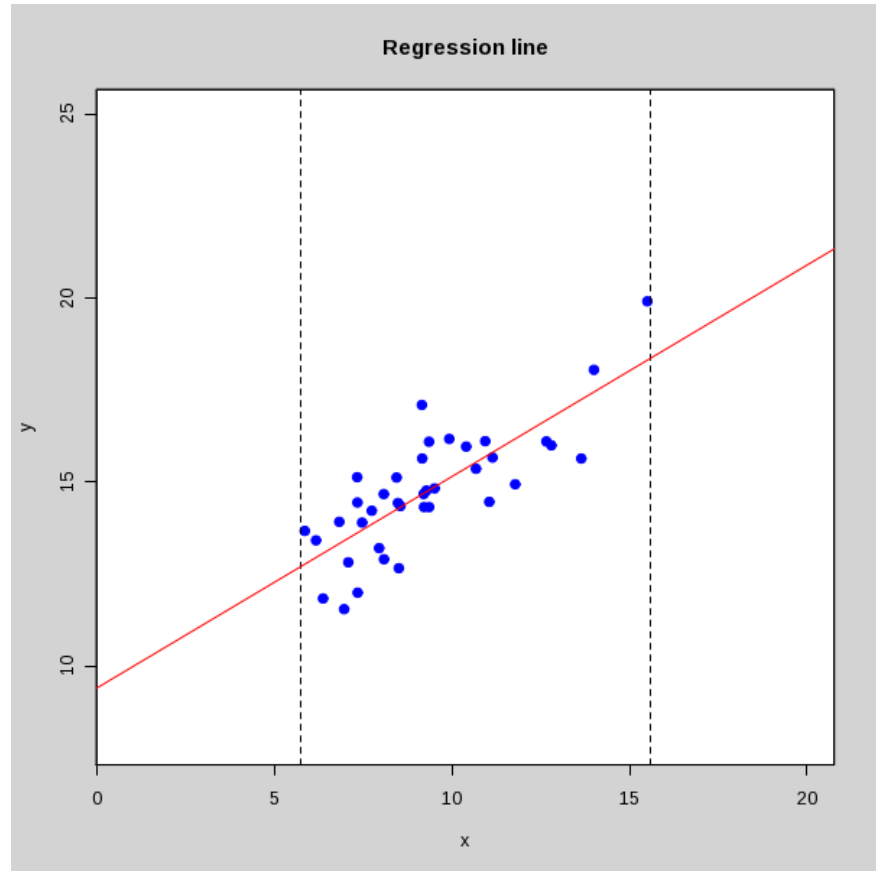

Gambar 1. Grafik Persamaan Garis Regresi Linier

Dari grafik Gambar 1 terdapat sumbu x dan sumbu y. Di mana sumbu $\mathrm{x}$ adalah variabel independen atau 
variabel prediktor atau bebas. Dan sumbu y adalah variabel dependen atau variabel respon atau terikat.

Regresi linear berganda mempunyai lebih dari satu variabel prediktor dan hanya satu variabel respon[7].

Contoh persamaan garis regresil linear di Persamaan 1. $\mathrm{Y}=9.4+0.7 * \mathrm{X}$

III. METODE

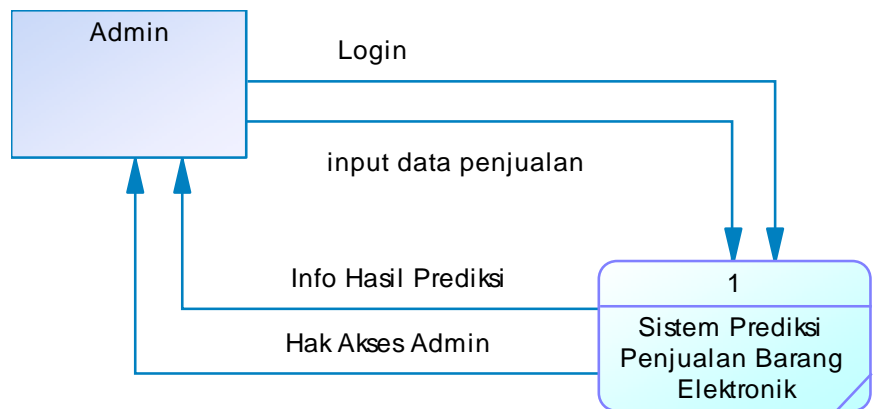

Gambar 2. Diagram Konteks

Gambar 2 adalah Diagram Konteks di mana, Admin melakukan input dataset penjualan yang terdiri dari data penjualan pertahun. Admin dapat menghitung ramalan dengan menggunakan dataset yang telah diinputkan. Admin Kemudian dapat melaporkan hasil prediksi. Proses selanjutnya yaitu admin menginputkan dataset penjualan. Data penjualan kemudian tersimpan ke database penjualan. Data penjualan ini kemudian direkap dan dihitung menggunakan metode Regresi Linier Berganda. Setelah dihitung maka akan keluar hasil prediksi yang akan tersimpan ke tabel hasil prediksi.

Perancangan interface merupakan perancangan tampilan awal antarmuka terhadap aplikasi yang akan dibuat nantinya. Gambar 3 merupakan perancangan interface tampilan utama dari aplikasi prediksi penjualan

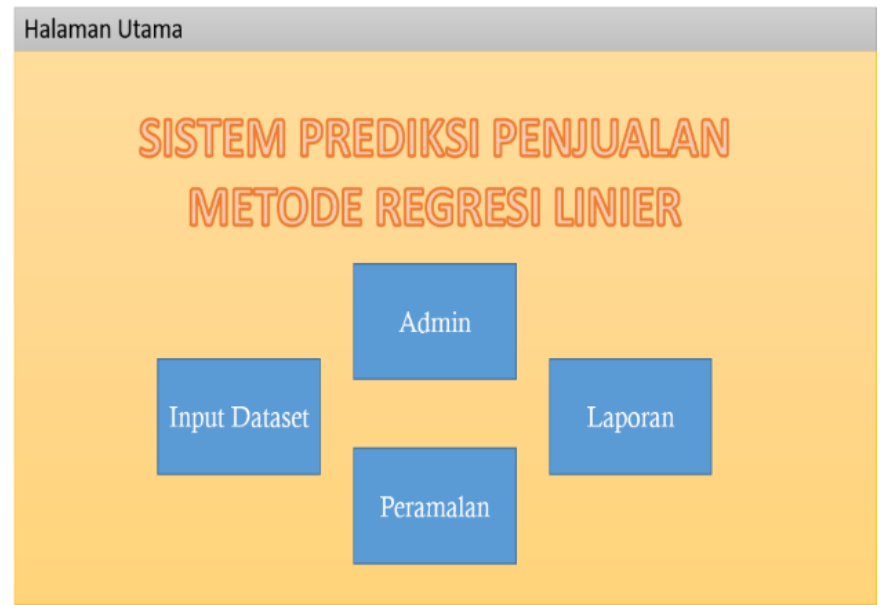

Gambar 3. Halaman Menu Utama

Pada halaman menu utama Gambar 3 terdapat empat menu yang dapat digunakan, yaitu menu Admin untuk memasukan data admin, Input Dataset untuk memasukkan data penjualan, menu Peramalan digunakan untuk menghitung peramalan penjualan, dan menu Laporan untuk mengetahui laporan akhir penjualan.

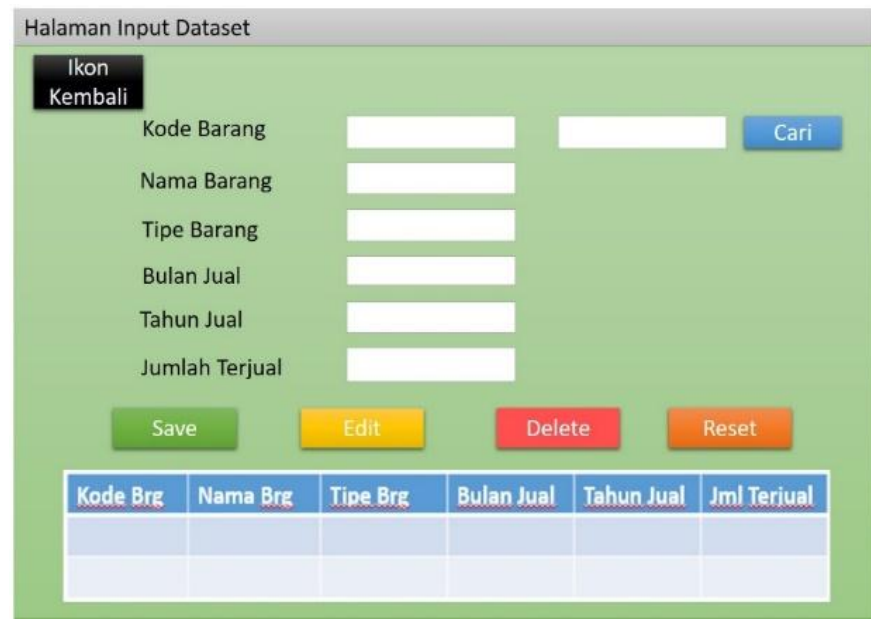

Gambar 4. Halaman Input Dataset

Pada menu Gambar 4 kita dapat melihat data penjualan barang elektronik, untuk melihat data penjualan barang elektronik admin harus melakukan penginputan data penjualan terlebih dahulu.

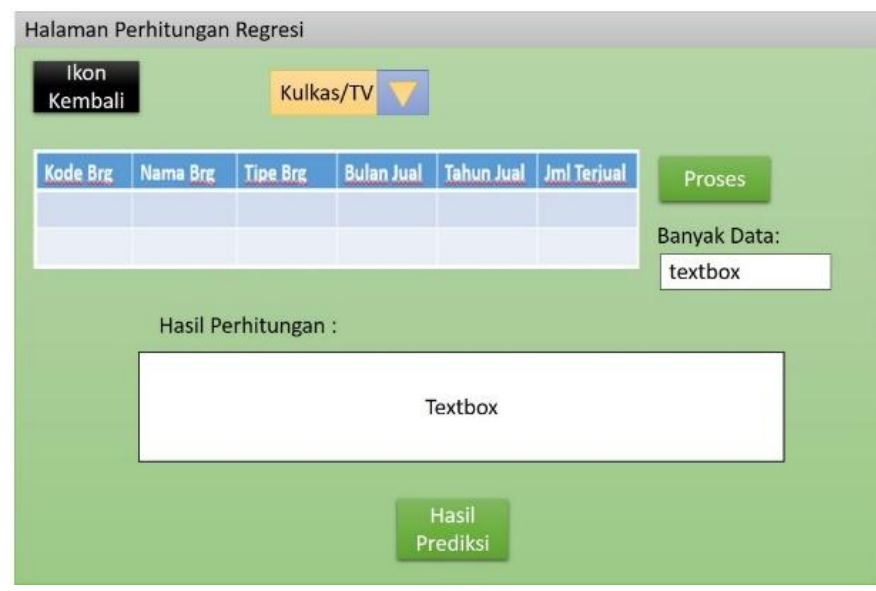

Gambar 5. Halaman Peramalan

Pada menu Gambar 5 admin akan melakukan proses peramalan atau forecasting. 


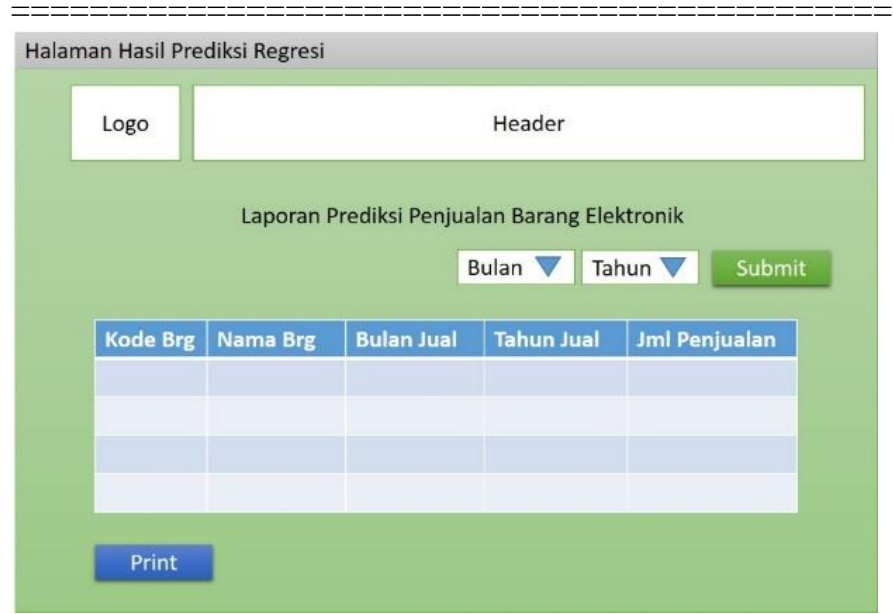

Gambar 6. Halaman Laporan

Pada menu Gambar 6 admin dapat melihat laporan peramalan penjualan barang elektronik serta mencetaknya dengan urutan bulan dan tahun.

\section{HASIL}

Implementasi dari sistem peramalan penjualan dengan menggunakan metode Regresi Linier Berganda ini terdiri dari beberapa form yang memiliki fungsifungsi tersendiri. Form-form tersebut akan tampil secara berurutan sesuai dengan urutan yang telah terprogram setelah pemakai masuk ke dalam sistem:

1) Menu Login

Menu Login ini berfungsi untuk masuk kedalam proses aplikasi agar bisa menghapus,mengedit dan menambah data yang akan diperlukan dengan memasukan username dan password yang tepat admin akan masuk ke menu utama.

2) Halaman Utama

Pada tampilan menu utama yang mempunyai 4 sub menu yaitu input dataset, admin, peramalan, dan laporan.

3) Halaman Input Dataset

Halaman ini berfungsi untuk menginputkan data penjualan perbulan yang kemudian akan disimpan di database dan digunakan untuk peramalan penjualan. Didalamnya terdapat textbox kode barang, nama barang, bulan jual, tahun jual dan jumlah terjual. Textbox X1, $\mathrm{X} 2, \mathrm{X} 3$, dan $\mathrm{Y}$ adalah perwakilan data dari nama barang, bulan jual, tahun jual dan jumlah terjual.

4) Halaman Admin

Pada halaman admin mempunyai beberapa textbox untuk inputan diantaranya: username, password, nama, dan jenis kelamin.

5) Halaman Peramalan

Halaman peramalan untuk menampilkan hasil peramalan dari data yang sudah diinputkan di halaman input dataset. Pada Gambar 7 juga terdapat perhitungan presentasi error dari data hasil peramalan yang ditampilkan di datagridview.

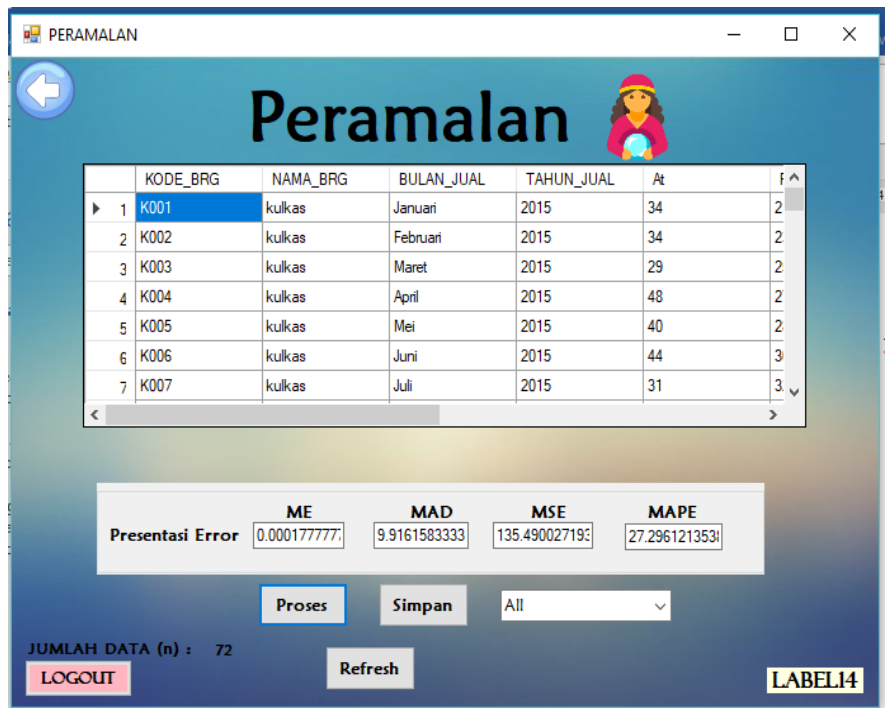

Gambar 7. Halaman Peramalan

6) Halaman Laporan

Pada Gambar 8 terdapat combobox untuk memilih barang apa yang akan dicetak laporannya. Di sini ada 3 pilihan yaitu "All" untuk semua barang, "kulkas" untuk barang kulkas dan "TV" untuk barang televisi.

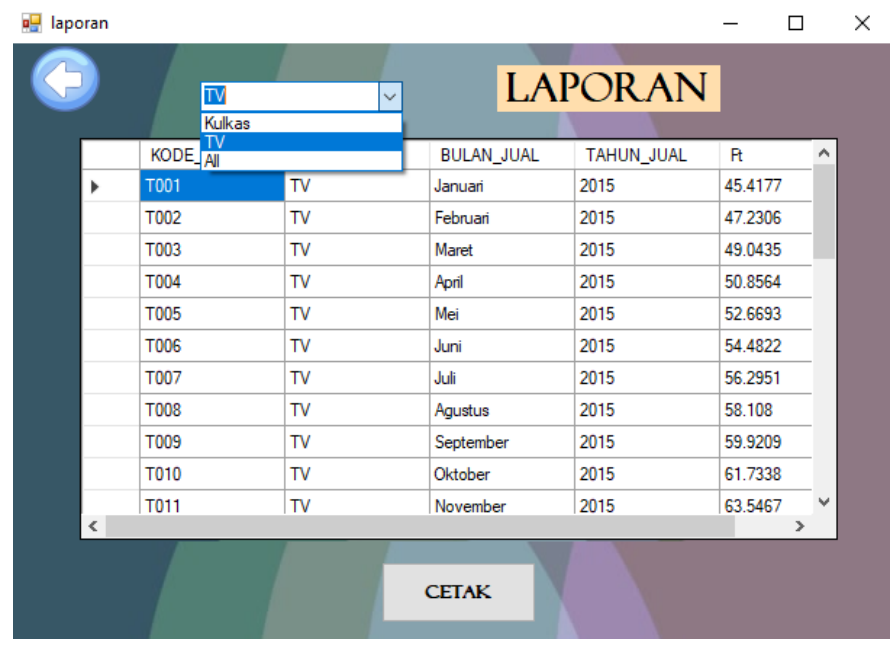

Gambar 8. Halaman Laporan

Perhitungan:

(1) $72 \beta_{0}+10,8 \beta_{1}+468 \beta_{2}+144 \beta_{a}=3161$

(2) $10,8 \beta_{0}+1,8 \beta_{1}+70,2 \beta_{2}+21,6 \beta_{a}=517$

(3) $468 \beta_{0}+70,2 \beta_{1}+3900 \beta_{2}+936 \beta_{3}=22102$

(4) $144 \beta_{0}+21,6 \beta_{1}+936 \beta_{2}+336 \beta_{a}=6342$

$\beta_{0}=\frac{3161-10,8 \beta_{1}-468 \beta_{2}-144 \beta_{3}}{72}$

(2) $10,8\left(\frac{3161-10,8 \beta_{1}-468 \beta_{2}-144 \beta_{3}}{72}\right)+1,8 \beta_{1}+70,2 \beta_{2}+21,6 \beta_{3}=517$

(3) $468\left(\frac{3161-10,8 \beta_{1}-42}{72}\right)+70,2 \beta_{2}-144 \beta_{1}+3900 \beta_{2}+936 \beta_{3}=22102$

(4) $144\left(\frac{3161-10,8 \beta_{1}-468 \beta_{2}-144 \beta_{3}}{72}\right)+21,6 \beta_{1}+936 \beta_{2}+336 \beta_{3}=6342$

Maka hasilnya

$Y^{\prime}=-4,423+238,0556 X_{1}+1,8129 X_{2}+0,4167 X_{3}$ 
Hasil Y' inilah yang kemudian akan di implementasikan ke sistem prediksi penjualan regresi linier berganda. Dengan menghasilkan presentasi error sebagai berikut:

$\mathrm{ME}=0,000$

$\mathrm{MAD}=9,9162$

$\mathrm{MSE}=135,49$

MAPE $=27,2961$

Gambar 9 merupakan tampilan peramalan dengan 72 sampel barang Elektronik yakni Kulkas dan Televisi.

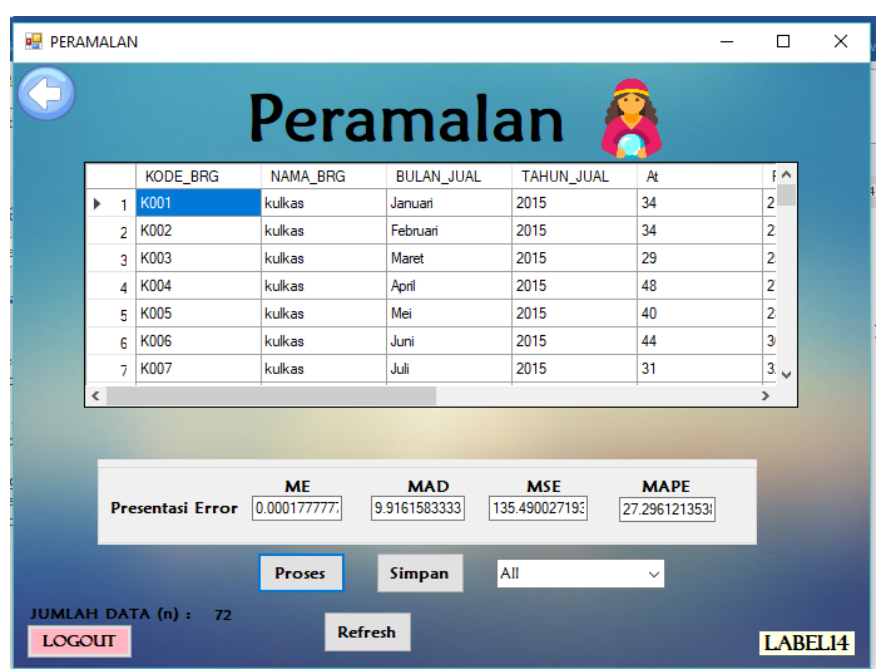

Gambar 9. Hasil Peramalan

\section{KESIMPULAN}

Dari penelitian ini didapatkan hasil peramalan dengan mengambil dua barang yakni peramalan penjualan kulkas dan televisi sebanyak 72 sampel akan menghasilkan:

$\mathrm{ME}=0,000$

$\mathrm{MAD}=9,9162$

$\mathrm{MSE}=135,49$

$\mathrm{MAPE}=27,2961$

\section{DAFTAR PUSTAKA}

[1] Junaidi, Bentuk Fungsional Regresi Linear (Aplikasi Model dengan Program SPSS). Jambi: Fakultas Ekonomi dan Bisnis Universitas Jambi, 2015.

[2] N. Nafi'iyah, "Penerapan Regresi Linear dalam Memprediksi Harga Jual Mobil Bekas," in SENABAKTI, Surabaya, 2015.

[3] A. Yusuf, H. Ginardi, dan I. Arieshanti, "Pengembangan Perangkat Lunak Prediktor Nilai Mahasiswa Menggunakan Metode Spectral Clustering dan Bagging Regresi Linier," J. Tek. ITS, vol. 1, no. 2, hal. A246-A250, Sep 2012.

[4] N. Nafi'iyah, "Perbandingan Regresi Linear, Backpropagation Dan Fuzzy Mamdani Dalam Prediksi Harga Emas," Pros. SENIATI, vol. 0, no. Book-2, Des 2016.

[5] P. Sulardi, T. Hendro, dan F. R. Umbara, "PREDIKSI KEBUTUHAN OBAT MENGGUNAKAN REGRESI LINIER," Pros. SNATIF, vol. 0, no. 0, hal. 57-62, Sep 2017.

[6] T. I. Andini, W. Witanti, dan F. Renaldi, "Prediksi Potensi Pemasaran Produk Baru Dengan Metode Naïve Bayes Classifier Dan Regresi Linear," J. Fak. Huk. UII, hal. 88533, 2016.

[7] D. Kurniawan, Regresi Linier (Linear Regression): Forum Statistika. Yogyakarta: Pustaka Pelajar, 2008. 